\title{
Flipped Computer Science Classes
}

\author{
R. Robert Gajewski \\ Warsaw University of Technology \\ Faculty of Civil Engineering \\ Al. Armii Ludowej 16, 00-637 \\ Warszawa Poland \\ Email: rg@il.pw.edu.pl
}

\author{
Marcin Jaczewski \\ Warsaw University of Technology \\ Faculty of Civil Engineering \\ Al. Armii Ludowej 16, 00-637 \\ Warszawa Poland \\ Email: mjacz@il.pw.edu.pl
}

\begin{abstract}
Computer Science (CS) classes have been supported for ten years by multimedia materials in the form of podcasts. Even such materials did not improve quality of learning outcomes. In order to change this the idea of flipped classroom (FC) was used but situation did not change radically, so survey concerning students opinion on FC was conducted. Comparison of results of survey show big differences in attitude to FC and learning between students in Poland and students in United States or Canada. Conclusion of this research is sad-it is very difficult to motivate Polish digital natives to learn..
\end{abstract}

\section{INTRODUCTION}

I DEA of inverting education is already nearly fifteen years old. One of the first papers in that field was published in 2000 [1]. This paper describes two parts of subject taught at Miami University while using the inverted classroom concept and analyzes the outcomes. Numerous technologies offered completely new possibilities for students to learn away from the classroom, while school period was used to perform collaborative experiments and worksheets. Authors of the paper concluded that the idea of inverted classroom offers alternatives for various learning styles and report that students favor that strategy. A different outline and evaluation of flipped education within a huge, primarily based on lectures, computer science course was published in 2002 in [2]. In this project new multimedia and video streaming application eTech was employed to change a course. In-class lectures were substituted by recorded lectures and auxiliary materials which could be viewed by students in the Internet independently. This make it possible to utilize the live period in the class for team problem solving facilitated by tutors. Another interesting paper in that field was published one year later in 2003 [3]. Within a series of five experiments hundreds of students from two different universities supervised by three different professors and six different teaching assistants took one semester long course in the field of casual and statistical reasoning in both traditional or online format. Within the frame of this project pre and post test results were compared. Features of the online experience

This work was supported by Warsaw University of Technology and grant no. 504/00713/1088/40.000103 which were helpful and which were not helpful were identified as well as most and least effective student learning strategies. Three years later a paper evaluating a web lecture intervention in a human-computer interaction course was published [4]. By utilizing lectures available in the Web before class more in-class period was used engaging students with hands-on tasks. Class time was spent on learning by doing rather than learning by listening. In 2007 Gannod presented his work in progress on how to use podcasts in an inverted classroom [5]. One year later Helmick presented integrated online courseware for computer science courses [6]. Last but not least in 2008 a paper describing how to use the inverted classroom to teach software engineering was published [7].

The present paper summarizes results of investigation presented in [8] and [9]. Starting from academic year 20122013 in some of groups podcasts (mainly software animations in the form of screencasts) were used in different way. Students were asked to watch podcasts at home. During classes students were supposed to be prepared to use software without any difficulties and to solve using it typical problems. First results of this experiment were to some extend promising. Students gained better scores in this case, but they were not very keen to spend additional time at home watching podcasts. They do prefer to be taught during classes. This problem was easily solved by adding simple point to subject regulations - students should be prepared to computer laboratories and this fact is checked by means of test before the class. In academic year 2013-2014 idea of flipped classroom was used for all groups - nine studying in Polish and two studying in English but only for part of material covering Computer Algebra System MathCAD Prime 3.0. Result of survey concerning students' satisfaction will be presented in the paper.

\section{FLIPPED CLASSROOM}

It is much more effective to watch, passive by nature, screencasts at home and solve problems with tutor in class than the other way round. This observation leads to idea to revert the situation. Why not to ask students to perform 
easier tasks at home and learn from podcasts independently and why not to solve during classes more difficult problems. Such situation is in agreement with Bloom's Revised Taxonomy [10], [11].

Blooms Taxonomy proposed in 1956 by panel of educators chaired by Benjamin Bloom is a categorization of learning objectives as well as activities split up into three areas: cognitive (mental skills, knowledge), affective (feelings, emotional areas and attitude) and psychomotor (manual and physical skills). The cognitive domain, the most significant in higher education, requires mental abilities and also knowledge. Within this domain one can find six major categories outlined from the most straightforward one: knowledge, comprehension, application, analysis, synthesis and finally evaluation. In the middle of 1990's cognitive domain has been modified. Titles associated with different types have been transformed from nouns to verbs. Moreover their order has been somewhat changed. Bloom's Revised Taxonomy demonstrates to a greater extent active way of thinking and also consists of six different categories: remembering, understanding, applying, analyzing, evaluating and finally creating. This taxonomy much better accounts for completely new behaviors and multimedia technology innovations (Fig. 1). Lower order thinking skills like remembering, understanding and applying are gained at home from podcasts which can be treated as recorded classes. Higher order thinking skills like analyzing, evaluating and creating are gained at the university. Such situation requires change of the role of academic staff from teachers to tutors. This idea was fully described in three books recently published by Bergmann and Sams [12], Bretzmann [13] or Walsh [14].

One of the best definitions of flipped class is given by Bergmann, Overmyer and Willie in The Daily Riff entitled The Flipped Class: Myths vs. Reality. "The traditional definition of a flipped class is: where videos take the place of direct instruction; this then allows students to get individual time in class to work with their teacher on key learning activities; it is called the flipped class because what used to be classwork (the "lecture" is done at home via teacher-created videos and what used to be homework (assigned problems) is now done in class."

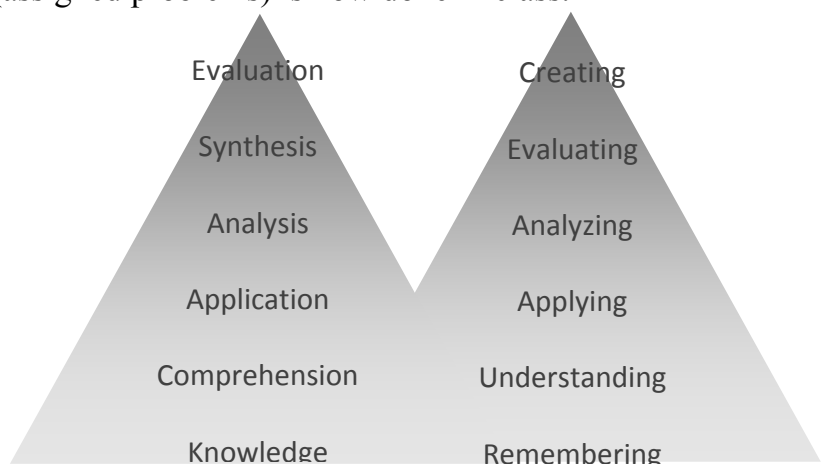

Fig. 1 Blooms Taxonomy and Revised Blooms Taxonomy
They also answered to the question what the flipped Classroom is. "A means to increase interaction and personalized contact time between students and teachers. An environment where students take responsibility for their own learning. A classroom where the teacher is not the "sage on the stage", but the "guide on the side". A blending of direct instruction with constructivist learning. A classroom where students who are absent due to illness or extra-curricular activities such as athletics or field-trips, don't get left behind. A class where content is permanently archived for review or remediation. A class where all students are engaged in their learning. A place where all students can get a personalized education."

\section{COMPUTER SCIENCE IN CIVIL ENGINEERING}

The place and role of Information Systems (IS), which can be treated in narrow sense as a term referring mainly to ICT, and Computer Sciences (CS) in curricula of Civil Engineering (CE) studies was described in previous paper [9]. Hardware and software information revolution has changed radically modern engineering workplace. The exact description of how transformation and circulation of information in the construction industry can and should look like can be found in [15]. In this work there are distinguished three groups of information: about the function, about the structure and about structure's behavior (Fig. 2). In all stages of transformation, it is important to use computer tools. The process of analyzing the structure is invariably dominated by computer programs using the finite element method. In the process of synthesis, where there is room for optimization, there are also available computational tools, such as for example a spreadsheet Solver.

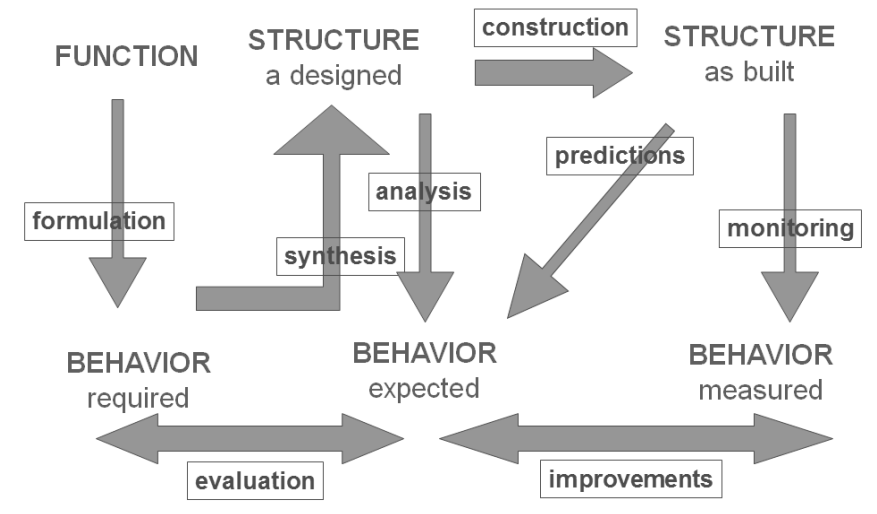

Fig. 2 Information flow in Civil Engineering

The last and the biggest block of classes is devoted to Computer Algebra System (CAS) namely to MathCAD Prime 3.0 which is described in books like [15] and [16]. Previous version of this program is better described in literature [17], [18] and [19]. Its presence in curricula of studies is a source of never ending discussions. In the opinion of many teachers students overuse MathCAD while preparing their design homework. It is enough that one 
person creates a file and all remaining can simply enter only the input data.

First part of MathCAD classes is devoted to solving classical mathematical problems like symbolic calculations, defining variables and functions, calculus (integrals, derivatives, limits), matrix and vector operators and functions and solving problems like linear and nonlinear equations, minimization and maximization. Second part is devoted to programming. In the beginning basic instructions (if, for, while) and control statements (return, continue, break) are introduced. The idea of this subject was inspired by the book [20]. Detailed list of screencasts for that part of the subject is in Table I.

All course materials are stored on learning platform Moodle. Taking into account different learning styles [21], [22] learning materials are available in different forms ranging from PDF files to screencasts (Fig. 3). The vast majority of materials are in the form of screencasts which are recordings of traditional classes (Fig. 4).

\section{SURVEY}

The research concerning students' satisfaction with flipped classroom was conducted in academic year 2013/2014 on a group of 222 students studying in Polish (PL) and a group of 51 students studying in English (EN). Out of 222 PL students the questionnaire was filled by 211 students. Similar data are for students studying in English. Questionnaire was filled by 49 out of 51 students. One third of students studying in English were foreigners.

Winter Academy (School) of Programming

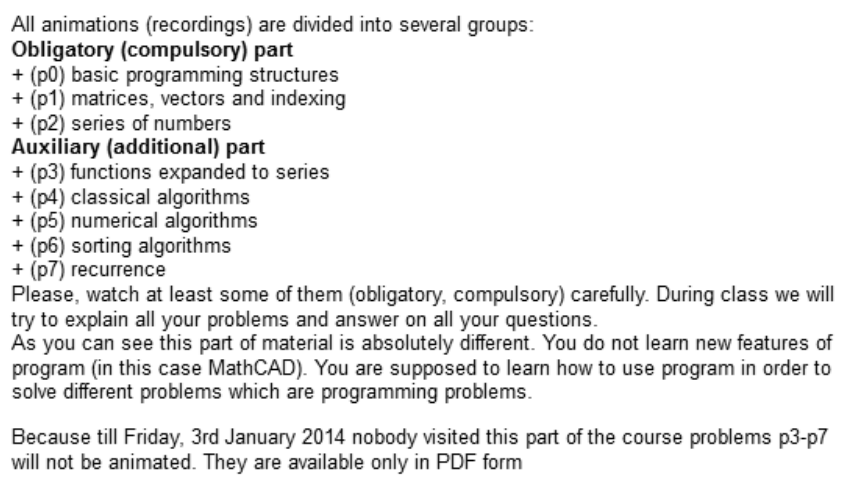
will not be animated. They are available only in PDF form

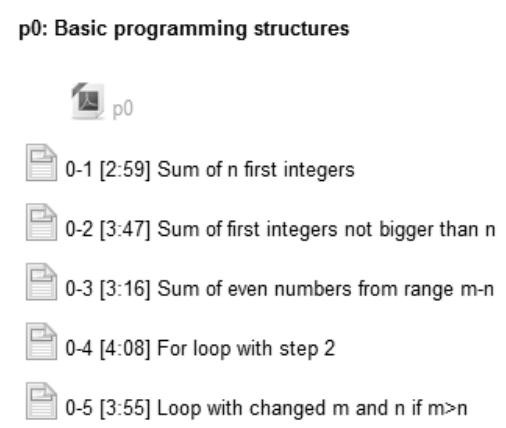

Fig. 3. Sample Learning Materials on Moodle platform

Four weeks of classes during which material covering text editor Word and spreadsheet Excel was discussed were

TABLE I.

Detailed Timetable of MathCAD Prime 3.0 Classes

\begin{tabular}{|c|c|c|c|}
\hline Week 1 - two hours & Week 2 - two hours & Week 3 - two hours & Week 4 - two hours \\
\hline $\begin{array}{l}\text { MathCAD Window } \\
\text { MathCAD ribbon } \\
\text { Customizing worksheet } \\
\text { Text and graphic regions } \\
\text { Math region } \\
\text { Grouping and formatting } \\
\text { Symbolic calculations } \\
\text { Simplifying expressions } \\
\text { Expanding expressions } \\
\text { Factoring expressions } \\
\text { Collect keyword } \\
\text { Coeffs keyword } \\
\text { Substitute keyword } \\
\text { Partial fractions } \\
\text { Series }\end{array}$ & $\begin{array}{l}\text { XY plots } \\
\text { Formatting XY plots } \\
\text { Range variables and XY plots } \\
\text { Parametric plots } \\
\text { Contour plots } \\
\text { Formatting contour plots } \\
\text { Arrays and tables } \\
\text { Creating arrays } \\
\text { Contour plots for scattered data } \\
\text { 3D plots }\end{array}$ & $\begin{array}{l}\text { Linear equations - matrix and } \\
\text { lsolve } \\
\text { Linear equations - solve block } \\
\text { Nonlinear system of equations - } \\
\text { solve block } \\
\text { Nonlinear system of equations - } \\
\text { polyroots } \\
\text { Finding roots } \\
\text { Parameterizing solve block } \\
\text { Optimizing functions } \\
\text { Optimizing with constraints } \\
\text { Distance between two curves } \\
\text { Solving ODEs with solve block }\end{array}$ & $\begin{array}{l}\text { Basic programming structures } \\
\text { Sum of } n \text { first integers } \\
\text { Sum of first integers not bigger } \\
\text { than } n \\
\text { Sum of even numbers from } \\
\text { range } m-n \\
\text { For loop with step } \\
\text { Loop with changed } m \text { and } n \text { if } \\
m>n \\
\text { Loop with step } k+2 \text { or }-2 \\
\text { Testing different solutions } \\
\text { (loops) } \\
\text { Not nested if and wrong nesting } \\
\text { Properly nested if }\end{array}$ \\
\hline $\begin{array}{l}\text { Identifiers } \\
\text { Defining variables } \\
\text { Defining functions } \\
\text { Units and label } \\
\text { Range variables } \\
\text { Derivatives } \\
\text { Integrals } \\
\text { Limits } \\
\text { Sums and products } \\
\text { Complex variables and functions }\end{array}$ & $\begin{array}{l}\text { Generation of arrays with if } \\
\text { Matrix operators } \\
\text { Matrix functions (1) } \\
\text { Matrix functions (2) } \\
\text { Linear equations } \\
\text { File access - output } \\
\text { File access - input } \\
\text { Curve fitting (1) } \\
\text { Curve fitting (2) } \\
\text { Keyword explict } \\
\text { Function root }\end{array}$ & $\begin{array}{l}\text { Creating a program } \\
\text { Defining functions } \\
\text { Using operators } \\
\text { Writing if statements } \\
\text { Writing if - else if statements } \\
\text { Function for different ranges } \\
\text { Loop with for } \\
\text { Loop with while } \\
\text { Structure try on error } \\
\text { Recursion }\end{array}$ & $\begin{array}{l}\text { Matrices, vectors and indexing } \\
\text { Minimum and maximum element } \\
\text { in vector } \\
\text { Minimum and maximum in one } \\
\text { function } \\
\text { Minimum element and its index } \\
\text { Sum of even numbers in vector } \\
\text { Series of numbers } \\
\text { "Theory" of series of numbers } \\
\text { Series with for and while loops } \\
\text { Slow convergence series } \\
\text { Alternative stop condition } \\
\text { Alternatives and art of } \\
\text { programming }\end{array}$ \\
\hline
\end{tabular}


2-2 [3:32] Slow convering series

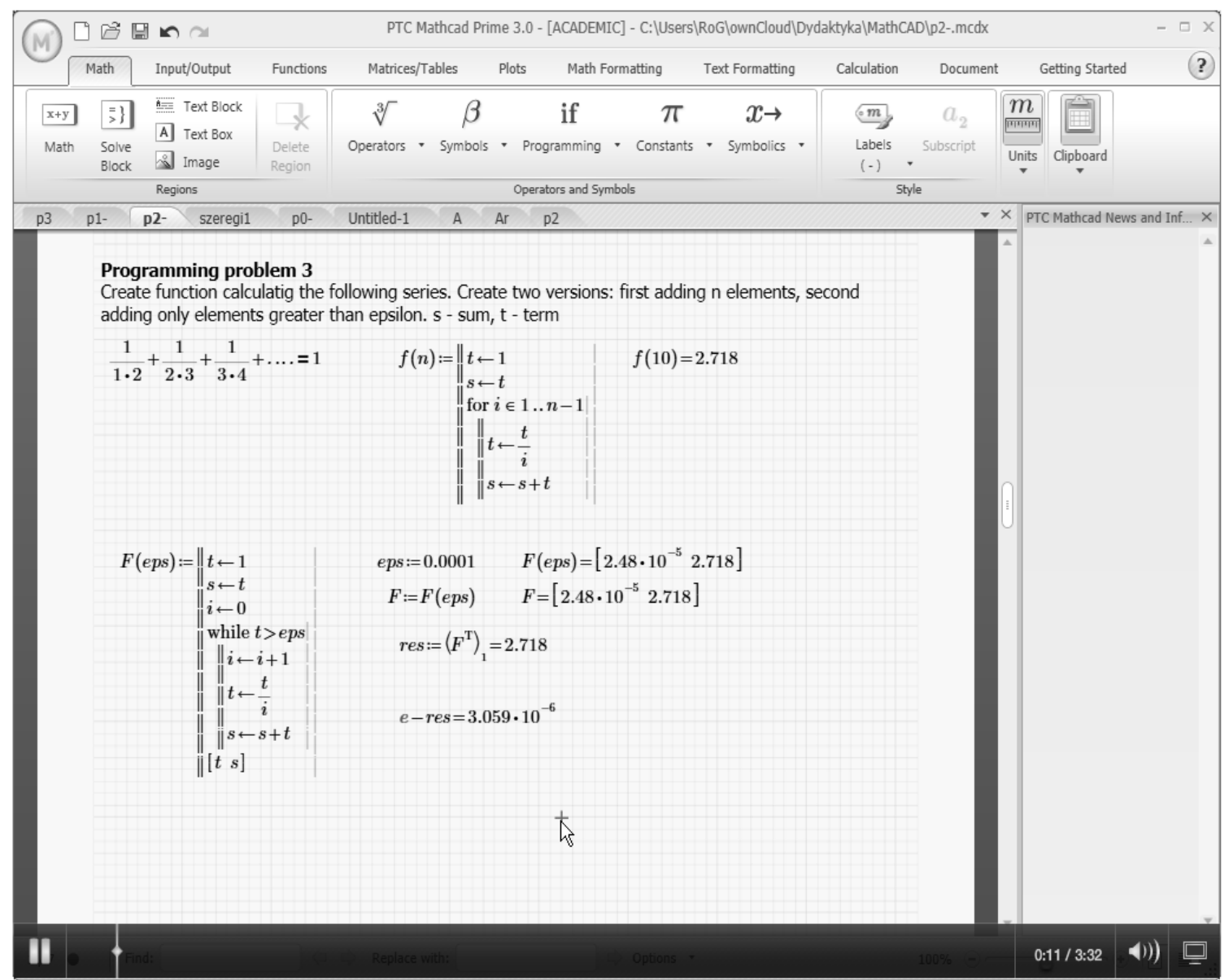

Fig. 4. Sample Screencast - Slow Converging Series

carried out in the traditional manner. In the computer laboratory equipped with 30 workstations there were two teachers. One of them demonstrated with multimedia projector solutions of the sample problems. The second teacher assisted students.

In order to perform survey Google Docs were used (Fig. 5, Fig. 6).

\section{1 responses}

View all responses

\section{Summary}

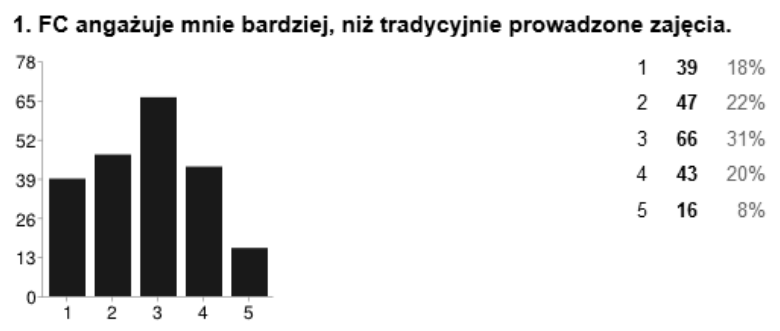

Fig. 5. Survey for Polish language students
Questionnaire used in this survey consists of fifteen closed form questions and 6 opened form questions. Due to the nature of answers all questions were divided into three groups. In order to compare results of survey with other outcomes some of the questions were based on similar surveys: first one conducted in Canada [27] and second one described in blog Flipping with Kirch conducted by Mary Kirch from United States.

\section{9 responses}

View all responses

\section{Summary}

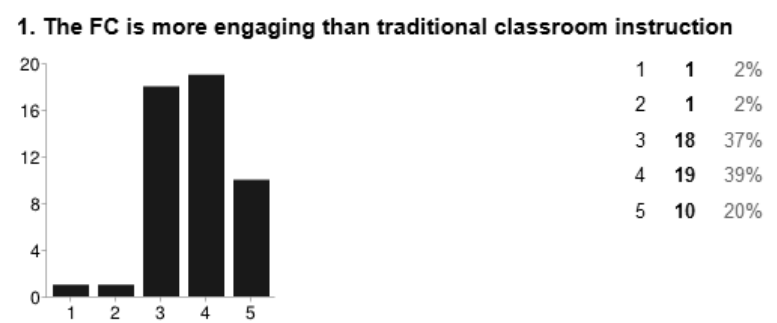

Fig. 6. Survey for English language students 
Observations from traditional classes were rather pessimistic. More than half of the students did not follow the presentation and did not perform similar tasks to those presented by the teacher. As presented in previous article [9] this material was rather unknown for students but they were simply not interested in learning new things. It is rather difficult to motivate digital natives to learn [23]. This is still a very important and significant problem even there were many books written on that subject [24]. The answer to this question is difficult when we consider digital natives who don't care and who also think that they know everything [25] in the field of subjects like Applied Computer Sciences and Computing in Civil Engineering. Mendler presents one of the existing solutions - five key processes that motivate: emphasizing effort, creating hope, respecting power, building relationships and expressing enthusiasm. But digital natives being real partners for learning [26] are difficult and demanding partners.

\section{V.RESULTS OF SURVEY}

Scale of answers for all first five questions is from "strongly agree" to "strongly disagree". Results for Polish language and English language students were compared with surveys from Canada. First of the asked questions was about level of engagement in traditional classroom instruction and flipped classroom (Fig. 7).

$40 \%$ of students studying in Polish language strongly disagree or disagree with the statement what is in accordance with the observation, that nearly half of the students was not interested in traditional classes. Answers of students studying in English language are closer to the answers from survey conducted in Canada.

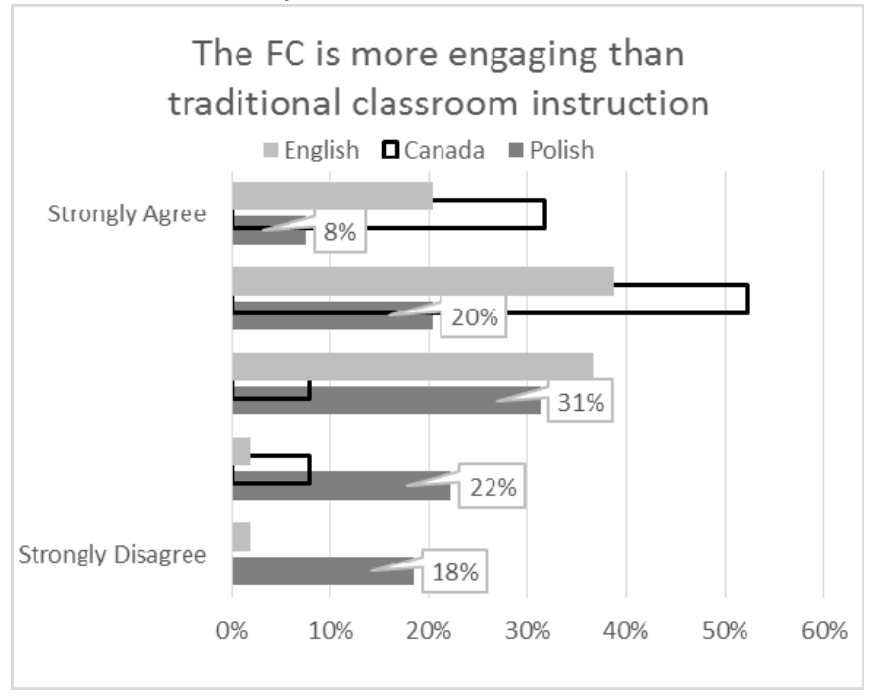

Fig. 7. Answers on question 1.1

Second question from that group was about potential recommendation of flipped classroom to a friend (Fig. 8).

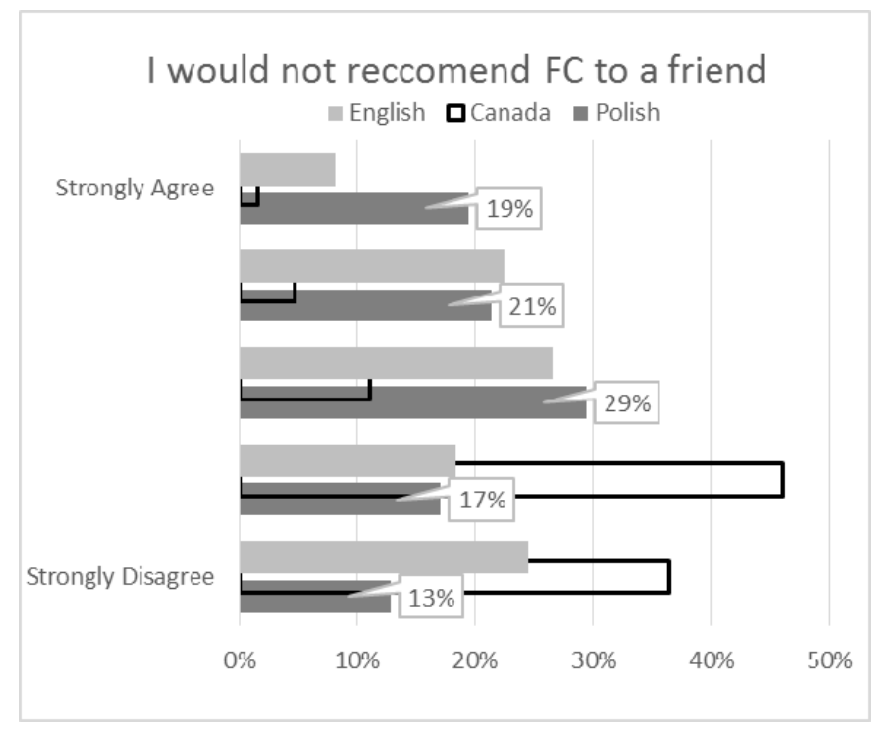

Fig. 8. Answers on question 1.2

For this question answers of students studying in Polish and English languages are similar but they definitely differ from the results of survey conducted in Canada. Nearly six times more students studying in Polish language in comparison to Canadian agree or strongly agree with the statement that they would not recommend flipped classroom to a friend.

Next question (statement) was very simple - I like watching lessons on video (Fig. 9). In this case answers for all three groups were very similar.

Fourth question in this group of questions was about bigger motivation to learn in the flipped classroom mode (Fig. 10).

In the case of this question answers of students studying in Polish language differ from the answers of two other groups. Nearly $40 \%$ of them strongly disagree or disagree with that statement that they are more motivated to learn in flipped classroom mode.

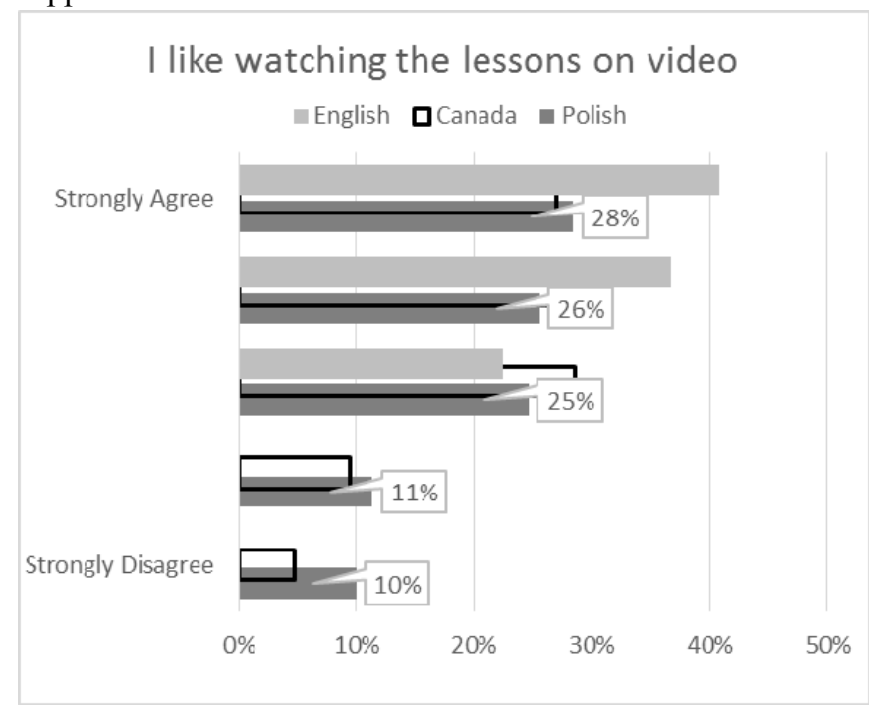

Fig. 9. Answers on question 1.3 


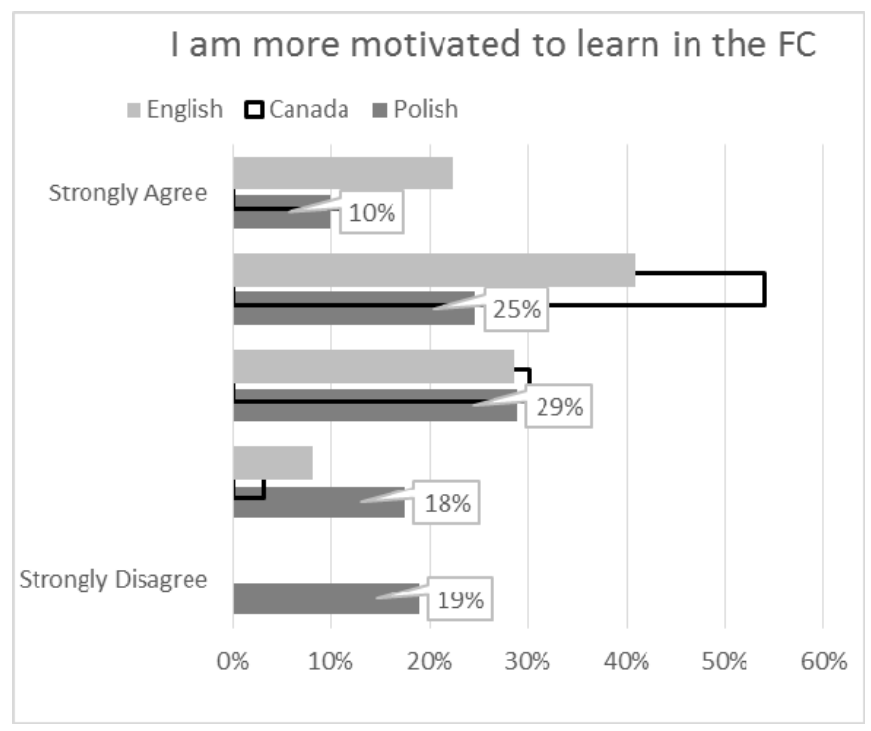

Fig. 10. Answers on question 1.4

The last question in this group is about improvement of learning in flipped classroom mode (Fig. 11).

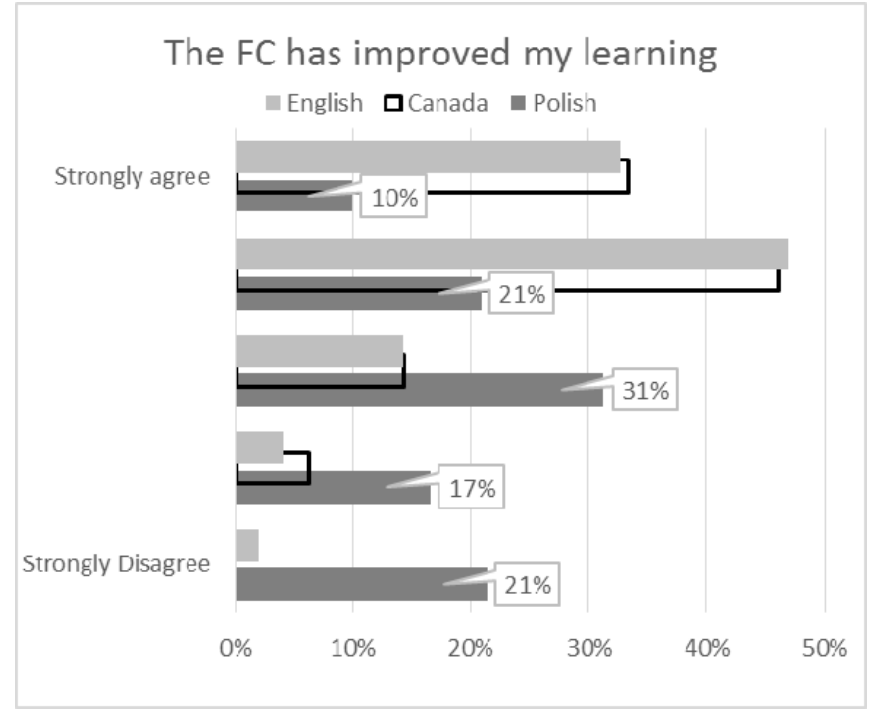

Fig. 11. Answers on question 1.5

Also in the case of this question answers obtained for students studying in Polish language are definitely different from results for two other groups. Nearly $40 \%$ of them strongly disagree or disagree with that statement. Answers for students studying in English and answers from survey in Canada are nearly the same. Nearly $80 \%$ agree or strongly agree with statement that flipped classroom has improved learning.

Second group of five questions is based on research conducted by Mary Kirch. Also in this case answers are on scale but they differ from question to question.

First question in this group is about rating flipped classroom. Scale of answers is from "very bad" to "very good" (Fig. 12).

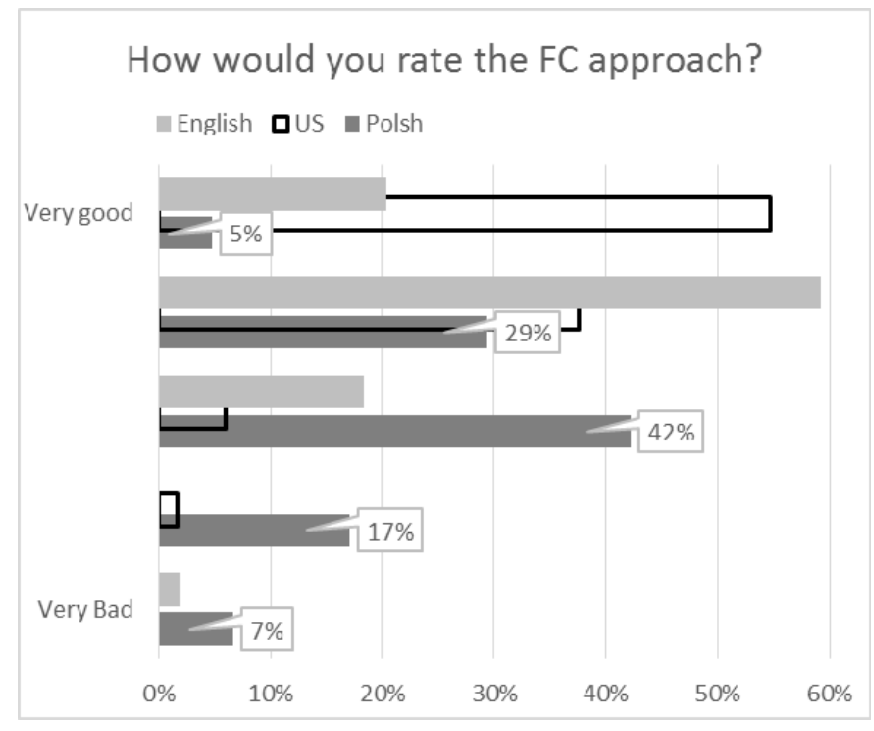

Fig. 12. Answers on question 2.1

Also in the case of this question answers for all groups are different. American students are most enthusiastic more than $90 \%$ rated flipped classroom approach as very good or good. Students studying in Polish are definitely less enthusiastic and more skeptical - nearly $25 \%$ of them rated flipped classroom approach as very bad or bad.

Next question in this group compared feelings how flipped classroom helps to learn the material in comparison to traditional approach (Fig. 13).

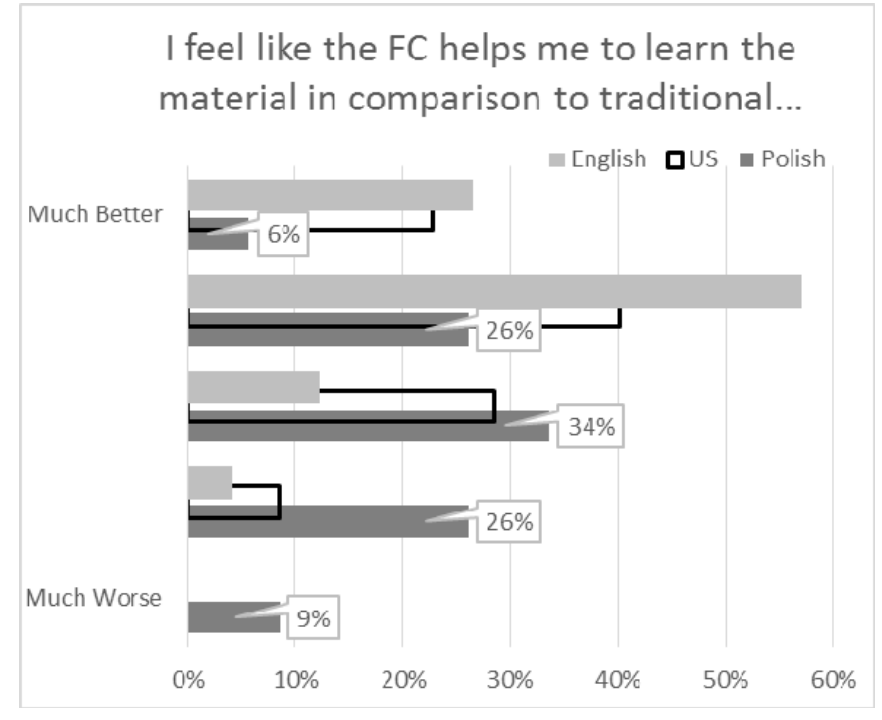

Fig. 13. Answers on question 2.2

Answers to this question are to some extend surprising. Number of answers much better or better is among students studying in English the highest - nearly $85 \%$ of such answers. Traditionally students studying in Polish gave the highest number of negative answers - 35\% of them answered that flipped classroom helped them to learn in comparison to traditional approach much worse or worse.

Fourth question was about feelings towards flipped classroom approach. Scale of the answers was from "I hate it" to "I love it" (Figure 14). Results in this point differ also 
because American scale was four point scale without neutral answer. Students were supposed to express only negative or positive feelings.

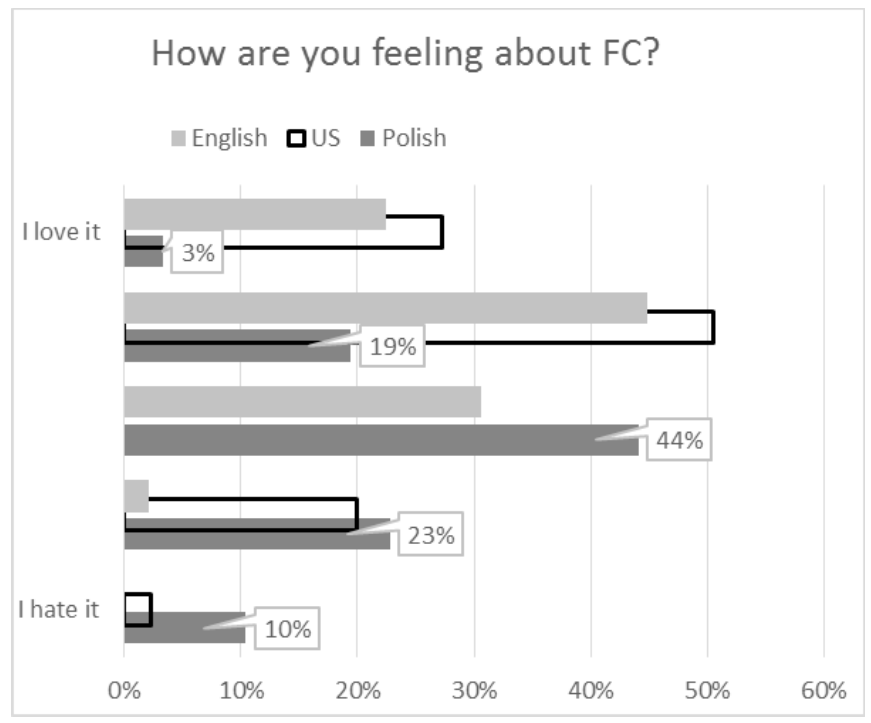

Fig. 14. Answers on question 2.3

As in the case of previous questions for students studying in Polish language the number of definitely positive answers I love it is the lowest - only $3 \%$.

In next point question how much did you learn in flipped classroom in comparison to traditional was asked (Fig. 15).

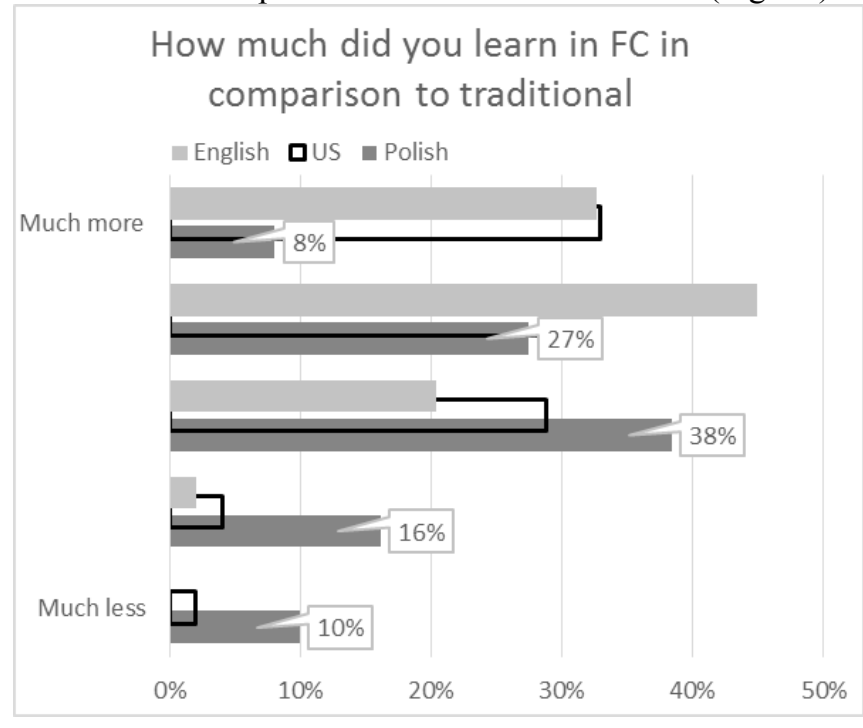

Fig. 15. Answers on question 2.4

More than $25 \%$ of Students studying in Polish language answered that they learned much less or less while more than $30 \%$ of students studying in English language or American students answered that they learned much more.

The last question was: how much were you challenged as a student in flipped classroom comparing to traditional one (Fig. 16).

Results for all three groups are in the case of this question very similar.

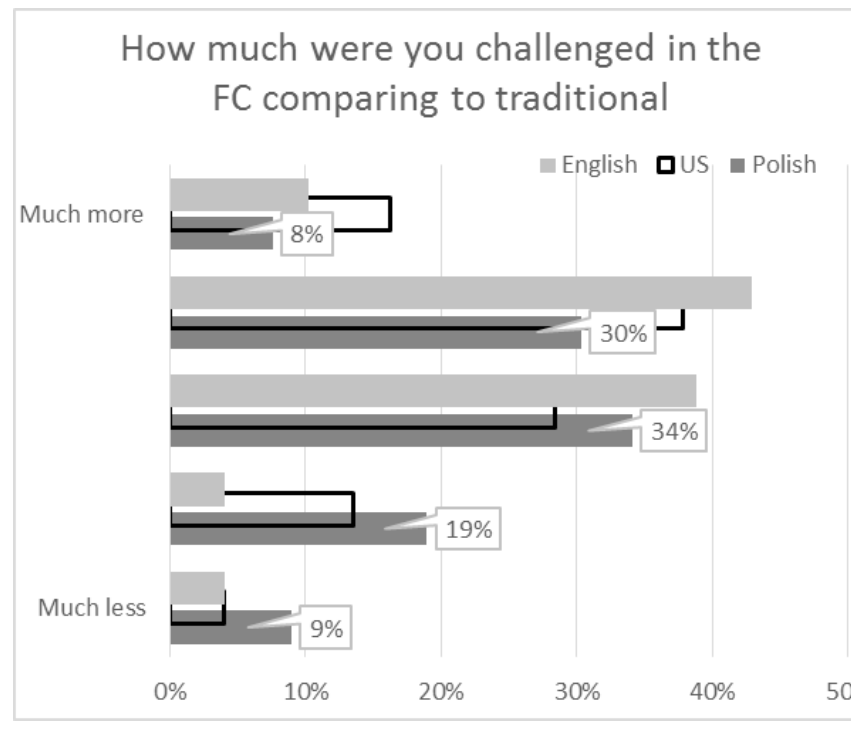

Fig. 16. Answers on question 2.5

\section{FINAL REMARKS}

One of the pressures on universities is the rapid development of new information and communication technologies for the provision of education and training. Wide opportunities in open and distance learning create new markets. Moreover the principle of life-long learning extends the age groups to which university can offer education. Additionally the principles of new techniques can be applied to traditional markets - regular intramural students. All Polish universities willing to use modern information and communication technologies face common opportunities, threats and constraints. A constant struggle between pressure to change and fear and resistance to change is visible in Poland. Teachers' attitudes are a major obstacle to the introduction of change. There is an internal brake on the efforts to make changes through using new technologies: resistance from people. Reference can be made to a "frozen middle" resisting attempts to change from both the top of the institutions (authorities) and from the bottom (students). Students' demands are a powerful factor forcing universities to exploit the potential of new technologies to improve learning experience. But the question "how to change the unchanging" is still open [28]. Moreover one should add to this question a new one - "how to motivate digital natives to learn?" [23].

Flipping the classroom is not the only way in which "how to change" and "how to motivate" problems can be solved. One of them is classification of learners using linear regression [29], because proper classification of learners is one of the key aspects in e-Learning environments .Second possibility is to enhance online educational environment what can be obtained by providing platform side intelligent functionalities in the shape of a recommender system or learning path builder [30]. Another possibility is to use system that allow the organization of a set of teaching and learning activities and meets, at its highest level of detail all the elements that compose the curriculum: setting goals and content, design and development of activities and 
evaluation, organization of space and time, and providing the necessary resources [31]. Next chance is to implement a Learner-centered learning which is constructivism based and Competence directed in which we define general competencies, domain competencies and specific course competencies [32]. Last but not least there are also another innovative teaching methods for blended learning like for example Drawer [33] or recognizing different learning styles while designing e-courses [34].

\section{ACKNOWLEDGMENT}

The authors wish to thank L. Wlasak, T. Dubilis and T. Warda for their support during flipped classroom experiment and survey. Thanks are also due to Dean of Faculty of Civil Engineering Professor H. Zobel who allowed us to conduct this educational experiment. Last but not least the authors wish to thank all students who filled very long questionnaire at the end of semester.

\section{REFERENCES}

[1] M. J. Lage, G. J. Platt, and M. Treglia, "Inverting the Classroom: A Gateway to Creating an Inclusive Learning Environment," Journal of Economic Education, vol. 31, no. 1, pp. 30-43, 2000. http://dx.doi.org/10.1080/00220480009596759

[2] J. Foertsch, G. Moses, J. Strikwerda, and M. Litzkow, "Reversing the Lecture/Homework Paradigm Using eTEACH ${ }^{\circledR}$ Web-based Streaming Video Software," Journal of Engineering Education, vol. 91, no. 3, pp. 267-274, Jul. 2002. http://dx.doi.org/10.1002/j.21689830.2002.tb00703.x

[3] R. Scheines, J. Smith, G. Leinhardt, and K. Cho, "Replacing lecture with Web-based course materials," Journal of Educational Computing Research, vol. 32, pp. 1-26, 2003.

[4] J. A. Day and J. D. Foley, "Evaluating a Web Lecture Intervention in a Human-Computer Interaction Course," IEEE Trans. on Educ., vol. 49, no. 4, pp. 420-431, Nov. 2006. http://dx.doi.org/10.1109/TE.2006. 879792

[5] G. C. Gannod, "Work in progress; Using podcasting in an inverted classroom," in Frontiers In Education Conference - Global Engineering: Knowledge Without Borders, Opportunities Without Passports, 2007. FIE 07. 37th Annual, 2007, pp. S3J-1-S3J-2. http://dx.doi.org/10.1109/FIE.2007.4418119

[6] M. T. Helmick, "Integrated Online Courseware for Computer Science Courses," in Proceedings of the 12th Annual SIGCSE Conference on Innovation and Technology in Computer Science Education, New York, NY, USA, 2007, pp. 146-150. http://dx.doi.org/10.1145/ 1268784.1268828

[7] G. C. Gannod, J. E. Burge, and M. T. Helmick, "Using the Inverted Classroom to Teach Software Engineering," in Proceedings of the 30th International Conference on Software Engineering, New York, NY, USA, 2008, pp. 777-786. http://dx.doi.org/10.1145/1368088. 1368198

[8] R. Gajewski, "Towards a New Look at Steaming Media," in WCCE 2013 10th IFIP World Conference on Computers in Education, vol. 2: Practice Papers, Torun: IFIP, 2013, pp. 98-103.

[9] R. Gajewski, L. Wlasak, and M. Jaczewski, "IS (ICT) and CS in Civil Engineering Curricula: Case Study," in Proceedings of the 2013 Federated Conference on Computer Science and Information Systems, Krakow: IEEE, 2013, pp. 717-720.

[10] B. S. Bloom, Taxonomy of Educational Objectives Book 1: Cognitive Domain, 2nd edition. Addison Wesley Publishing Company, 1984.
[11] L. W. Anderson, D. R. Krathwohl, P. W. Airasian, K. A. Cruikshank, R. E. Mayer, P. R. Pintrich, J. Raths, and M. C. Wittrock, A Taxonomy for Learning, Teaching, and Assessing: A Revision of Bloom's Taxonomy of Educational Objectives, Abridged Edition, 2nd ed. Pearson, 2000.

[12] J. Bergmann and A. Sams, Flip Your Classroom: Reach Every Student in Every Class Every Day. International Society for Technology in Education, 2012.

[13] J. Bretzmann, Flipping 2.0. Bretzmann Group LLC, 2013.

[14] K. Walsh and P. J. Walsh, Flipped Classroom Workshop in a Book, 1 edition. Kelly Walsh, 2013.

[15] H. Wesselingh and H. de Waard, Calculate \& Communicate with Mathcad Prime. Delft: VSSD, 2012.

[16] B. Maxfield, Essential PTC $®$ Mathcad Prime $₫$ 3.0: A Guide for New and Current Users, 1 edition. Academic Press, 2013.

[17] R. W. Larsen, Introduction to Mathcad 15, 3rd ed. Prentice Hall, 2010.

[18] B. Maxfield, Essential Mathcad for Engineering, Science, and Math, Second Edition, 2nd ed. Academic Press, 2009.

[19] P. Pritchard, Mathcad: A Tool for Engineering Problem Solving $+C D$ ROM to accompany Mathcad, 2nd ed. McGraw-Hill Science/Engineering/Math, 2011.

[20] D. Harel and Y. Feldman, Algorithmics: The Spirit of Computing, 3rd ed. Addison-Wesley, 2004.

[21] F. Romanelli, E. Byrd, and M. Ryan, "Learning Styles: A Review of Theory, Application, and Best Practices," American Journal of Pharmaceutical Education, vol. 73, no. 1, pp. 1-5, 2009.

[22] C. Scott, "The Enduring Appeal of 'Learning Styles," Australian Journal of Education, vol. 54, no. 1, pp. 5-17, 2010. http://dx.doi.org/10.1177/000494411005400102

[23] G. B. Johnson, "Student Perceptions on the Flipped Classroom." The University of British Columbia, 2013.

[24] L. Wlasak, M. Jaczewski, T. Dubilis, and T. Warda, "How to Motivate Digital Natives to Learn?" in WCCE 2013 10th IFIP World Conference on Computers in Education, vol. 3: Book of Abstracts, Torun: IFIP, 2013, pp. 78-79.

[25] J. E. Brophy, Motivating Students to Learn. Routledge, 2010.

[26] A. Mendler, Motivating Students Who Don't Care: Successful Techniques for Educators. National Educational Service, 2000.

[27] M. R. Prensky, Teaching Digital Natives: Partnering for Real Learning. Corwin, 2010.

[28] R. R. Gajewski, "How to change the unchanging? Restructuring Polish universities for the XXI century," in TelE-learning, The Challenge for the Third Millennium, 2002, pp. 297-300.

[29] C. Mihaescu, "Classification of Learners Using Linear Regression," in Proceedings of the 2011 Federated Conference on Computer Science and Information Systems, 2011, pp. 717-721.

[30] M. C. Mihăescu, "The Design of eLeTK - Software System for Enhancing On-Line Educational Environments," in Proceedings of the 2012 Federated Conference on Computer Science and Information Systems, 2012, pp. 739-744.

[31] A. P. Cipres, H. M. Fardoun, and A. Mashat, "Cataloging Teaching Units: Resources, Evaluation and Collaboration," in Proceedings of the 2012 Federated Conference on Computer Science and Information Systems, 2012, pp. 825-830.

[32] J. Schreurs and A. Al-Huneidi, "Design of Learner-Centered constructivism based Learning Process," in Proceedings of the 2012 Federated Conference on Computer Science and Information Systems, 2012, pp. 1159-1164.

[33] F. A. Marco, V. M. R. Penichet, and J. A. G. Lázaro, "Drawer: an Innovative Teaching Method for Blended Learning," in Proceedings of the 2013 Federated Conference on Computer Science and Information Systems, 2013, pp. 727-734.

[34] O. Mironova, T. Rüütmann, I. Amitan, J. Vilipõld, and M. Saar, "Computer Science E-Courses for Students with Different Learning Styles," in Proceedings of the 2013 Federated Conference on Computer Science and Information Systems, 2013, pp. 735-738. 